Int. J. Electrochem. Sci., 14 (2019) $8720-8732$

\title{
Service Life Assessment of Lead and its Alloy Anodes During Zinc Electrowinning
}

\author{
Chang-jiang Yang*, Lv-xing Zhao, Xu Zhang
}

Faculty of Metallurgical and Energy Engineering, Kunming University of Science and Technology, Kunming 650093, P. R. China

*E-mail: chemdut@163.com, yangc@kmust.edu.cn

doi: $10.20964 / 2019.09 .10$

Received: 2 May 2019 / Accepted: 20 June 2019 / Published: 31 July 2019

Lead $(\mathrm{Pb})$ and its alloy anodes are widely used in the process of zinc electrowinning. It is important, yet difficult, to evaluate the service life of different anodes with varying components. In this work, electrochemical accelerated corrosion tests were investigated for the prediction of service life. Corrosion of pure $\mathrm{Pb}, \mathrm{Pb}-0.75$ wt.\% $\mathrm{Ag}$, and $\mathrm{Pb}-0.287$ wt.\% $\mathrm{Ag}-0.914$ wt.\% $\mathrm{Ca}$ anodes were investigated in the simulated electrolyte with and without manganese ion. Corrosion potentials, polarizing resistances, corrosion currents, and current efficiencies of the three typical anodes are further discussed. The semiempirical relationship between corrosion rate and current density was suggested to obtain consumption rates of $\mathrm{Pb}$-based anodes by rapid evaluation in the bench-scale experiments. Both the service life and the energy efficiency can be acquired according to the expression obtained.

Keywords: Corrosion rate; $\mathrm{Pb}$; Anode; Zinc electrowinning

\section{FULL TEXT}

(C) 2019 The Authors. Published by ESG (www.electrochemsci.org). This article is an open access article distributed under the terms and conditions of the Creative Commons Attribution license (http://creativecommons.org/licenses/by/4.0/). 